\title{
TEORIA DA PÓS-AVALIAÇÃO DA APRENDIZAGEM: UM OLHAR SOBRE A EVASÃO ESCOLAR
}

\author{
POST-EVALUATION THEORY: \\ Looking For Dropping-Out
}

\author{
Margeylson Ribeiro da Graça ${ }^{1}$ \\ Crislane Batista dos Santos ${ }^{2}$
}

\section{RESUMO}

A avaliação da aprendizagem é um assunto discutido amplamente. Basta uma consulta nos principais banco de publicações para se elencar o quantitativo das publicações. Através dessa pesquisa pode-se notar que o conjunto de pontos necessários ao docente após a avaliação da aprendizagem e antes da retomada da aula, carece de material teórico. Desta forma, utilizando como respaldo as contribuições de Jussara Hoffman, Cirpiano Luckesi, Pedro Demo, Mourão, dentre outros, foi montado um arcabouço sobre a avaliação a fim de justificar a existência de um momento após a avaliação que precisa ser pesquisado. Apresenta-se também uma breve relação do que a teoria da pós avaliação pode influenciar em alguns aspectos que colaboram para a evasão escolar. Para compor a teoria, foram utilizadas o estado da arte, pesquisa bibliográfica e quali-quantitativa como metodologias de pesquisa. Por fim, apresenta-se a carência de estudos sobre o momento após a avaliação da aprendizagem e antes da retomada do ensino, ponto este que influencia numa educação mais justa, que não preze pela manutenção das desigualdades e das injustiças sociais.

PALAVRAS-CHAVE: Aprendizagem. Avaliação. Evasão. Pós-Avaliação.

\section{ABSTRACT}

Learning evaluation is a widely discussed subject. Just a query to the major publications banks is necessary to list or quantify publications. Was noted that the set of points required for the teacher after the learning evaluation and before the class resumption needs theoretical material. Therefore, using Jussara Hoffman, Cirpiano Luckesi, Pedro Demo, Mourão, among others, a framework was built about the evaluation to justify the presence of a moment after evaluation that needs to be researched. After, presented a brief relation of what the post

\footnotetext{
${ }^{1}$ Mestre em Ciênciasda Educação pela FICS, Especialista em Docência Superior, Licenciado em Matemática, Bahcarel em Sistemas de Informação, Coordenador da Licenciatura em Computação do Instituto Federal de Educação, Ciênciae Tecnologia da Bahia e Professor de Programação do IFBA.Email:margeylsongraca@ifba.edu.br.

2 Mestra em Ciências da Educação pela FICS.Especialista em Educação Profissional Científica e Tecnológica pelo IFBA; Especialista em Neuroaprendizagem pela Unyleya.Especialista em Gestão Escolar e Coordenação Pedagógica pela Unyleya.Licenciada em Pedagogia pela UNIFACS.Coordenadora Pedagógica em São Francisco do Conde/Ba.Docente Escola Tercia Borges -Candeias/Ba. Email: crislaine.bs@hotmail.com
} 
evaluation theory can influence in some aspects that contribute to the dropout. To compose the theory, state of the art, bibliographic and quantitative/qualitative research were used as research methods. Finally, there is a lack of studies about the moment after the learning evaluation and before the teaching resumption, a point that influences a fairer education, which does not aim the maintenance of social inequalities and injustices.

KEY WORDS: Learning. Evaluation. Dropout. Post-evaluation.

\section{APRENDIZAGEM E AVALIAÇÃO}

Os aspectos escolares não definem o limite para a avaliação. Ao aplicar uma análise sobre o processo evolutivo da nossa espécie, percebe-se que através de fatores que demarcavam a nossa sobrevivência foram moldados muitos aspectos que trazemos até hoje. Tecnicamente, o que se anseia de um discente é que ele possa assimilar o que é visto no espaço escolar, armazenar este conhecimento, bem como seus fenômenos formadores, e ressignificá-lo de forma a utilizar no ambiente ao qual ele faz parte.

Este processo de armazenar, ressignificar e aprender, é o conceito de aprendizagem utilizado neste trabalho. Para tal, segue-se as concepções que circundam a aprendizagem.

\section{A aprendizagem segundo a biologia}

Fisiologicamente, o nosso corpo possui uma rede de células que se especializaram em assimilar, organizar e reter informação a fim de transformá-la em conhecimento. Estas células, conhecidas como neurônios, são interconectadas em estruturas complexas em vários órgãos pelo corpo, todavia, o cérebro é o responsável pelas características do aprendizado.

Ao longo da evolução humana o nosso órgão central nervoso se destacou em relação a outros mamíferos. Pesando cerca de 1,5Kg é relativamente grande, proporcionalmente, se comparado a outros animais. Apenas a nível de exemplo, se considerarmos a baleia azul, com seus $10 \mathrm{Kg}$ de massa encefálica, temos que este valor é apenas 0,005\% do seu peso corporal, enquanto em nós, em um indivíduo mediano, chega a ter $2 \%$ do seu peso (ROMANZOTI, 2013).

Durante muito tempo acreditou-se que o número de neurônios no cérebro era determinado pelo número de rugas deste, todavia, conforme Andrade (2015), as dobras vistas na parte mais superficial do cérebro (córtex) seriam pelo fato desta camada abrigar um número significativo de células que foram distribuídas ali ao longo do processo evolutivo dos mamíferos, todavia em nós humanos o número de neurônios é três vezes maior que, por exemplo, nos paquidermes.

As semelhanças e diferenças entre as estruturas físicas cerebrais podem ser observadas na Fig. 1 , que compara o cérebro humano com o do elefante africano. 

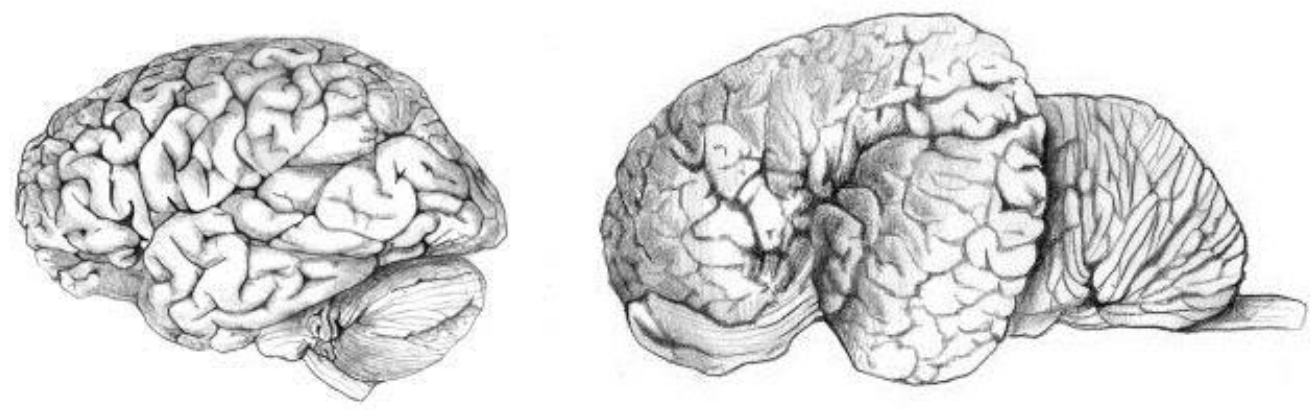

$5 \mathrm{~cm}$

Figura 1 - Comparativo entre os cérebros humano e do elefante.

Fonte: Adaptado de Novella (2014)

Estudos relatados por Tallinen et al. (2014), mostram que a rugosidade cerebral advém da pressão exercida pelo líquido espinhal que ele sofre durante a sua formação, ainda na fase embrionária.

Partindo desta concepção, migramos para a ideia do que é memória onde, conforme Mourão (2011, p.780), a "grosso modo, chamamos de memória a capacidade que os seres vivos têm de adquirir, armazenar e evocar informações". Este conceito objetivo de memória é campo vasto de investigação para a ciência, visto que muito é debatido a respeito.

No meio deste campo teórico, temos a ideia de que aprendizado é se apropriar de um determinado conhecimento, armazená-lo e fazer uso deste em outra situação. Logo, aprender, segundo Kolb e Whishaw (2002), é algo diretamente ligado ao ser humano e envolve ressignificar o conhecimento, mas não aplicado exclusivamente ao ambiente escolar e, principalmente, ligado a aspectos de sobrevivência.

Criar novos conhecimentos é dado como um conjunto de reações elétricas e químicas nos neurônios. Tais reações recebem o nome de sinapses e podem ser observadas na representação da Fig. 2.

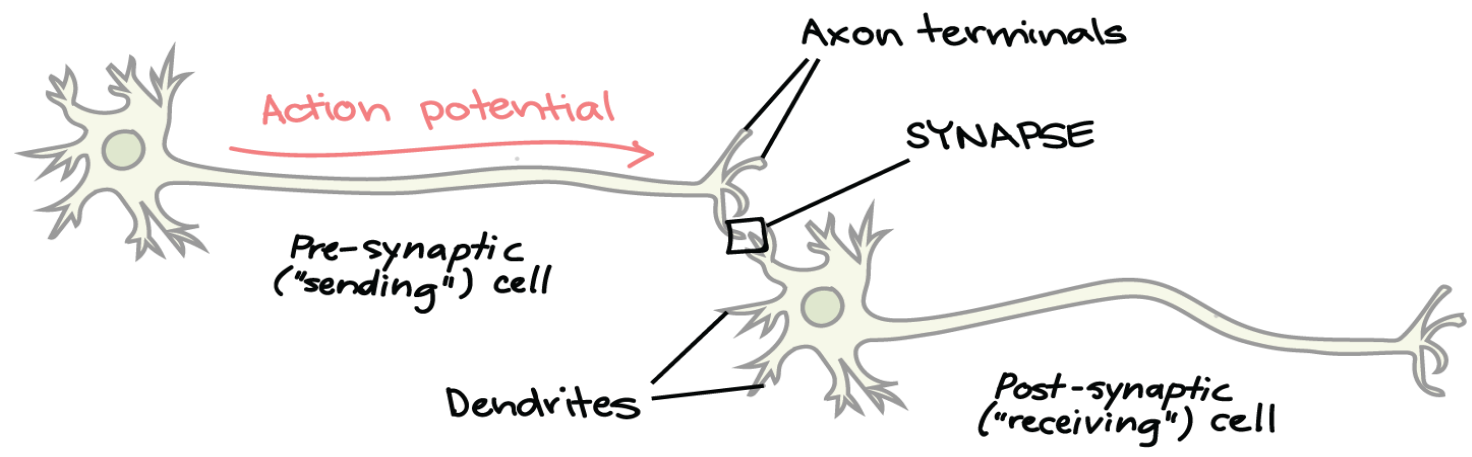

Figura 2 - Representação do neurônio e da sinapse. Fonte: Khan Academy, 2019 
Nesta complexa teia montada da relação entre sobrevivência, mente e aprendizagem, temos que:

o Sistema Nervoso (SN), por meio de seu integrante mais complexo, o cérebro, recebe e processa os estímulos ambientais e elabora respostas adaptativas que garantem a sobrevivência do indivíduo e a preservação da espécie (HALPERN et al. apud GUERRA, 2011, p.3)

Essa formação de memória passa por três processos distintos, onde podemos observar a percepção dos dados através dos nossos sentidos e armazenados na Memória SensorialMotora (MSM), onde ficará por um curtíssimo tempo (até 0.5 segundo) FAIGLE (s.d.). Os dados armazenados da MSM podem ser descartados ou armazenados na Memória de Curto Prazo (até 30 segundos) onde pode passar por um novo filtro e finalmente ser registrada na Memória de Longa Duração (MLD) (Ibidem). Na MLD, os dados ficam gravados de forma que podem registrados para toda a vida e, conforme Mourão e Faria (2015, p. 786), "ocorre durante determinadas fases do sono, e é por isso que o sono é fundamental para a consolidação de novas informações".

\section{Aprendizagem segundo aspectos subjetivos}

Vencido os aspectos biológicos, entra-se em categorias mais subjetivas do cérebro, onde podemos notar a construção de Piaget (1971) apresentando que a mente teria o papel de filtrar tudo o que e apresentado pelo mundo e transformar essa enxurrada de dados em informações com sentido e aplicação.

Os estudos relacionados à relação entre aprendizagem e o funcionamento do cérebro iniciaram, segundo Espinosa (2011), com o estudo intitulado Neuroeducation: Brain Compatible Learning Strategies, vinculado à Kansas University, o primeiro vinculado à Mind, Brain, and Education Society e categorizado com visionário, regendo norma cerca de 30 anos após a sua publicação.

Então, considerando os aspectos físicos e as interações elétricas e químicas do cérebro, bem com os estudos sobre aprendizagem de Piaget, temos que aprender nada mais é que interagir com o meio, registrar a interação em processos no cérebro (sinapses) e utilizar a informação em situações posteriores.

Embora possam existir diversos conceitos ligados à aprendizagem, neste trabalho considerase a perspectiva de David Ausubel (1982), caracterizando o conceito como um momento significativo em que a nova informação faz sentido para quem aprende, desde que apoiado em conceitos, ideias e proposições pré-existentes, claras e estáveis (MOREIRA, 2013).

Percorrendo a história da aprendizagem temos a filosofia que defendia, através de Locke (sec. XVII) e Hume (sec. XVIII), a ideia de que o indivíduo teria seu conhecimento definido pelas experiências. Essa história perpassa pela psicologia, onde destaca-se a obra de Immanuel Kant, "A crítica da razão pura" (1781), que descreve que todo sujeito tem uma razão básica que será modificada pelas experiências ao longo da história do sujeito. Já no século XX, apoiada em tais teorias, surgem as mais diversas teorias da aprendizagem (DIAZ, 2011). 


\section{Avaliação da aprendizagem}

Usando como base a interação do sujeito com o meio, há a necessidade da análise dessa interação a fim de perceber se a aprendizagem ocorreu. Essa percepção, conhecida como avaliação da aprendizagem, deve responder se o aluno conseguiu assimilar o conteúdo de formar que ele possa utilizar no meio social.

No meio educacional, temos um processo complexo no qual há a necessidade de traçar objetivos, meios para obter os resultados e formas de interpretar os resultados para, só então, se ter a ideia de até onde os objetivos foram alcançados (SANT'ANNA, 2010). Esse processo é a avaliação e a concepção de avaliação, como atenção dos docentes para os discentes, surgiu nos anos de 1930, entretanto só aporta no Brasil, no final dos anos de 1960 e entra para a LDB apenas em 1996 (LUCKESI, 2011).

O desafio da avaliação é conseguir traçar o perfil de aprendizagem da turma e não ser utilizada como classificatória (GRILLO et al., 2010), como objetos de temor (HOFFMANN, 2018).

É importante salientar que este trabalho não faz menção a um tipo específico de avaliação, já que o crucial é identificar na turma como esse momento deve ser tratado. Isso, conforme Graça (2018a), foi reforçado por uma pesquisa feita em sala onde 15 dos 20 discentes, Graf.1, responderam que se sentem nervosos no momento da avaliação. Tal dado mostra que o discente pode vir estigmatizado de outros processos avaliativos e isso pode influenciar no real papel da avaliação.

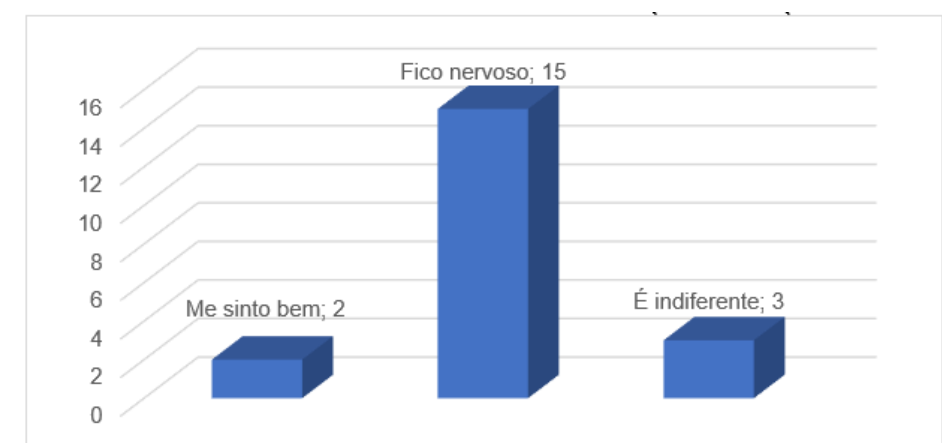

Gráfico 1- Sentimento dos discentes em relação à avaliação.

Fonte: Graça (2018a)

Outro dado importante é participar ao discente do papel da avaliação, visto que $61 \%$ dos alunos entrevistados (Graça, 2018b), responderam que a avaliação é pouco ou nada importante, Graf. 2, denotando que os alunos não conhecem o verdadeiro papel que avaliar exerce na construção do conhecimento. 


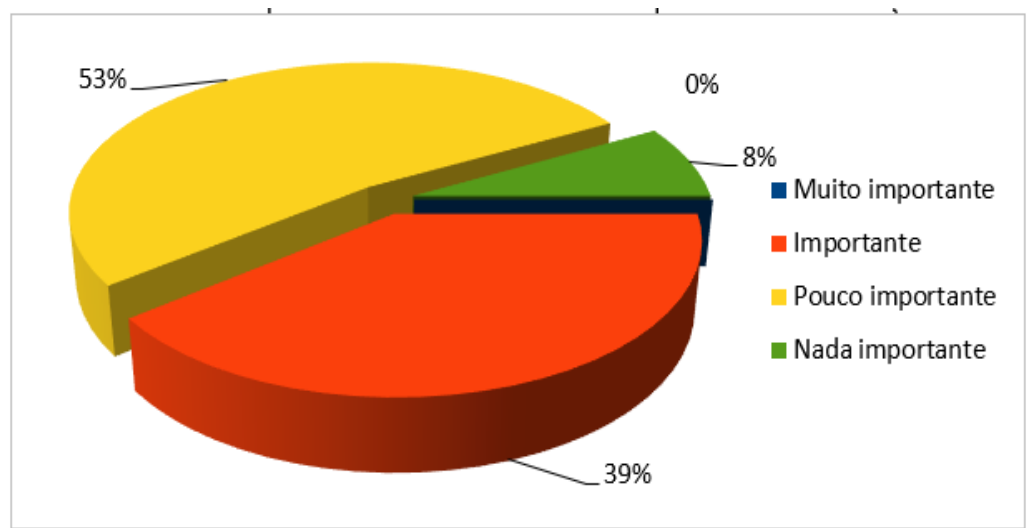

Gráfico 2 - Visão dos discentes sobre a importância da avaliação.

Fonte: Graça (2018b)

Esta é uma visão que mostra o estigma do aluno em relação ao que é avaliar, este estigma pode ter sido formado de processos anteriores e/ou da não compreensão do discente do processo. Isso deve ser um fator motivador para incluir o discente na construção do avaliar e, aos poucos, mudar a concepção da avaliação como algo ruim no meio educacional.

\section{Pós-avaliação ressignificando o trabalho docente}

Diante do real papel da avaliação, de fornecer um conjunto de dados sobre os quais o docente deve debruçar e repensar a sua prática, foi pensando, durante o período de pesquisa para a confecção da dissertação de mestrado do autor, a teoria da pós-avaliação da aprendizagem. Esta teoria categoriza um momento específico no processo ensino aprendizagem na qual o professor deve utilizar os resultados da avaliação para montar um perfil da turma e repensar todo o processo que utiliza para lecionar.

O modelo, proposto no comparativo da Fig.3, é inserido imediatamente após a avaliação, não importando o momento que esta ocorra, mas sim os resultados obtidos dela. Esses resultados devem fornecer ao professor uma visão sobre os nichos de aprendizado da turma, onde o docente deve analisar que a forma atual como determinado conteúdo foi compartilhado não conseguiu atingir a determinado grupo de alunos.
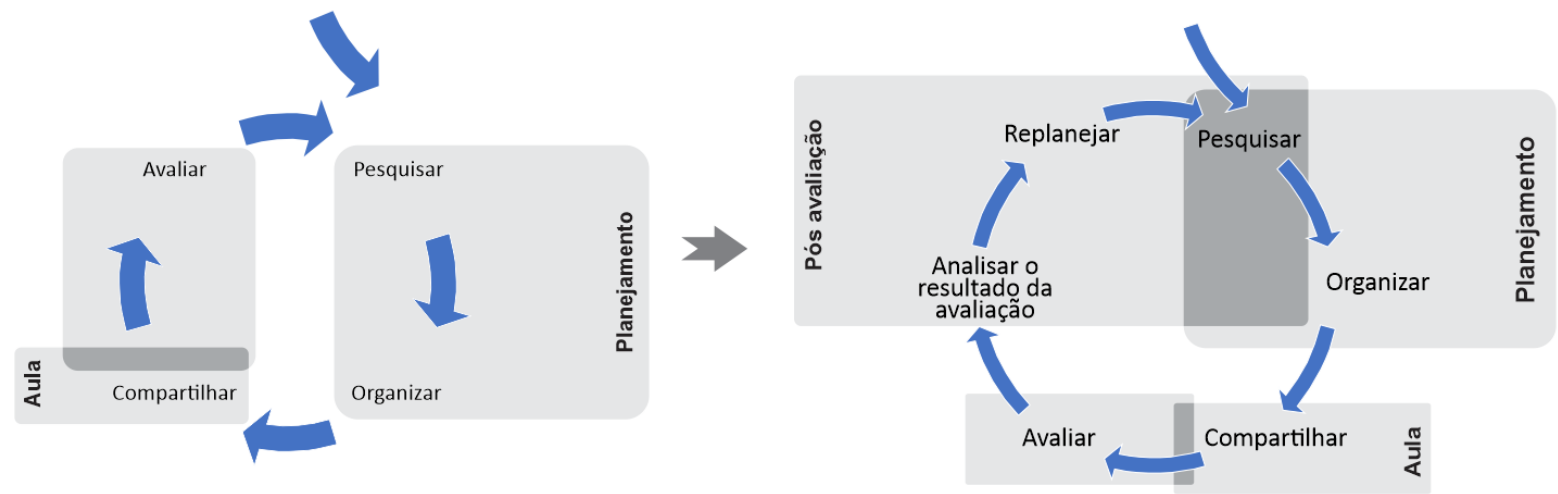

Figura 3 - Comparativo entre a visão do processo ensino-aprendizagem e o modelo acrescido da pós-avalaiação.

Fonte: Próprio Autor (2019) 
Pode-se notar no esquema proposto, que a pós-avaliação compartilha a pesquisa com a etapa do planejamento, visto que a primeira deve retroalimentar o segundo, visto que a forma como a aula foi dada anteriormente não surtiu efeito com a turma. Diante disto, não é meramente o conteúdo que deve ser pesquisado, mas sim outras metodologias de ensino para que o professor remodele sua aula e forneça, considerando as individualidades dos discentes, uma nova oportunidade para o aprendizado.

A pós-avaliação é proposta como um conjunto de métodos, técnicas e ferramentas que podem, e devem, ser mutáveis, considerando o resultado da avaliação e a realidade do professor, a fim de atingir como objetivo a real aprendizagem.

Os métodos fazem referência aos modelos de avaliação e de ensino que dos quais a teoria se apropria visando oportunizar ao professor um arcabouço de conhecimento para que possa reformular facilmente a sua prática. Quanto mais técnicas o docente conhecer e quanto mais este praticar tais técnicas, mais fácil torna-se trafegar por elas.

Nas técnicas temos que o professor não pode estar sozinho no momento da pós-avaliação. Pensar em um cenário de várias turmas, em várias instituições e com as cobranças sociais e pressões burocráticas, faz com o professor tenda à uma forma de lecionar mecanicista, já que atuar sozinho transforma todo o processo em ação dificultada. Desta forma, a sociedade, a instituição e os discentes devem fazer parte do planejar da construção do processo a fim de elaborar o melhor modelo que se encaixe àquela sociedade/turma.

E, por fim, ferramentas é o material de apoio que vai fornecer ao professor uma visão de como seu processo de ensino está atuando naquela turma. É interessante frisar que este material pode se referir a qualquer etapa do processo de ensino-aprendizagem, já que o papel desta é colaborar com professor para conhecer de perto quem são seus alunos e moldar nichos específicos para atuar de forma mais precisa.

Basicamente, qualquer momento, ideia, ferramenta computacional o não, que colabora com o professor em entender como a sua turma se comportou diante do conhecimento apresentado e como ela reagiu a este conhecimento, pode compor o conceito de pós-avaliar.

\section{Pós-avaliação, o primeiro teste.}

Após o desenvolvimento da ideia do que é a pós avaliação, este conceito foi praticado em uma turma do componente curricular Algoritmos, da Licenciatura em Computação do Instituto Federal de Educação, Ciência e Tecnologia da Bahia, Campus Valença, bem como no Ensino Médio Integrado em Informática, nos mesmos componente curricular e lócus.

A ideia original foi sentar diante do resultado da avaliação da aprendizagem e elencar quais os assuntos e o quantitativo de dissentes que teve dificuldades em determinado conteúdo. Traçado o mapa, Fig. 4, foi definido que se o quantitativo de alunos que acertaram apenas $25 \%$ de uma questão somados ao quantitativo de alunos que erraram a questão fosse maior que metade da turma, o assunto seria abordado novamente em sala. 


\begin{tabular}{|c|c|c|c|c|c|c|c|c|c|}
\hline \multirow[b]{2}{*}{$\begin{array}{l}\text { Assunto sobre } \\
\text { Algoritmos na } \\
\text { avaliação }\end{array}$} & \multirow[b]{2}{*}{ Questão } & \multicolumn{5}{|c|}{ Acerto da Questão } & \multirow[b]{2}{*}{ Ação * } & \multirow[b]{2}{*}{ Quando } & \multirow[b]{2}{*}{ Como reavaliar } \\
\hline & & $25 \%$ & $50 \%$ & $75 \%$ & $100 \%$ & $\begin{array}{c}\text { Errou a } \\
\text { questão } \\
(0 \%)\end{array}$ & & & \\
\hline Conceitos Básicos & 1 & 0 & 4 & 0 & 5 & $(0 \pi)$ & $\begin{array}{c}\text { Trabalho em } \\
\text { grupo }\end{array}$ & $\begin{array}{l}\text { Imediatamente na } \\
\text { próxima aula }\end{array}$ & $\begin{array}{c}\text { Análise do trabalho; } \\
\text { Perguntas em aulas } \\
\text { futuras }\end{array}$ \\
\hline $\begin{array}{l}\text { Conceito de } \\
\text { Variáveis }\end{array}$ & 2 & 0 & 2 & 0 & 9 & 5 & $\begin{array}{c}\text { Trabalho em } \\
\text { grupo }\end{array}$ & $\begin{array}{c}\text { Imediatamente na } \\
\text { próxima aula }\end{array}$ & $\begin{array}{c}\text { Análise do trabalho; } \\
\text { Perguntas em aulas } \\
\text { futuras }\end{array}$ \\
\hline $\begin{array}{l}\text { Conceito de } \\
\text { Controle de Fluxo }\end{array}$ & 3 & 3 & 0 & 0 & 7 & 6 & Reabordah & $\begin{array}{c}\text { Dissolver nos } \\
\text { próximos conteúdos }\end{array}$ & $\begin{array}{c}\text { Lista de exercicios; } \\
\text { Perguntas em aulas } \\
\text { futuras }\end{array}$ \\
\hline $\begin{array}{l}\text { Conceitos de } \\
\text { Operadores Lógicos }\end{array}$ & 4 & 2 & 1 & 0 & 12 & 1 & $\begin{array}{l}\text { Trabalho em } \\
\text { grupo }\end{array}$ & $\begin{array}{l}\text { Imediatamente na } \\
\text { próxima aula }\end{array}$ & $\begin{array}{c}\text { Análise do trabalho; } \\
\text { Perguntas em aulas } \\
\text { futuras }\end{array}$ \\
\hline $\begin{array}{l}\text { Prática de } \\
\text { Operadores } \\
\text { Matemáticos }\end{array}$ & 5 & 1 & 2 & 0 & 7 & 6 & $\begin{array}{c}\text { Trabalho em } \\
\text { grupo }\end{array}$ & $\begin{array}{c}\text { Imediatamente na } \\
\text { próxima aula }\end{array}$ & $\begin{array}{c}\text { Análise do trabalho; } \\
\text { Perguntas em aulas } \\
\text { futuras }\end{array}$ \\
\hline $\begin{array}{l}\text { Prática de Entradas } \\
\text { e Saídas }\end{array}$ & 6 & 2 & 3 & 0 & 5 & 6 & Reabordar & $\begin{array}{c}\text { Dissolver nos } \\
\text { próximos conteúdos }\end{array}$ & $\begin{array}{c}\text { Lista de exercícios; } \\
\text { Perguntas em aulas } \\
\text { futuras }\end{array}$ \\
\hline $\begin{array}{l}\text { Prática de Controle } \\
\text { de Fluxo }\end{array}$ & 7 & 1 & 0 & 4 & 2 & 9 & Reabordak & $\begin{array}{c}\text { Dissolver nos } \\
\text { próximos conteúdos }\end{array}$ & $\begin{array}{c}\text { Lista de exercícios; } \\
\text { Perguntas em aulas } \\
\text { futuras }\end{array}$ \\
\hline $\begin{array}{l}\text { Prática de Laços de } \\
\text { Repetição }\end{array}$ & 8 & 1 & 0 & 0 & 2 & 13 & Reabordar & $\begin{array}{c}\text { Dissolver nos } \\
\text { próximos conteúdos }\end{array}$ & $\begin{array}{c}\text { Lista de exercícios; } \\
\text { Perguntas em aulas } \\
\text { futuras }\end{array}$ \\
\hline
\end{tabular}
\begin{tabular}{|l|l|}
\hline $\begin{array}{l}\text { * Critério utilizado para abordar } \\
\text { novamente o conteúdo }\end{array}$ & Respostas erradas $+25 \%$ de acerto > = metade da turma \\
\hline
\end{tabular}

Figura 4 - Exemplo de ferramenta utilizada no conceito de pós-avaliação.

Fonte: Próprio Autor (2019)

Cabe ressaltar, que a nova abordagem foi planejada para ser totalmente diferente da inicial, a nível de exemplo, consideremos que ao utilizar a metodologia da sala de aula invertida, devese agora tentar outra forma, como, por exemplo, o uso de objetos lúdicos de aprendizagem.

\section{A pós-avaliação e sua relação com a evasão}

Diversos autores relatam sobre o uso incorreto da avaliação da aprendizagem professores. Graça (2018b) expõe alguns desses olhares destacando aqui o papel de disciplinar o discente; manutenção das desigualdades em sala de aula; criar um sistema classificatório; e da criação de termos para definir o aluno, como aluno bom ou ruim.

Este uso da avaliação, que não está alinhado com o seu real objetivo, cria no aluno um estigma do processo de avaliar e, conforme Figueiredo e Salles (2017), tem um papel significativo na evasão escolar. Outro ponto, ainda relacionado à evasão escolar, é "Conflitos e dilemas enfrentados pelos professores no que se refere à relação entre seu saber fazer e as características dos alunos "fracos" e/ou das camadas populares" (Ibidem).

Neste contexto em que a avaliação acaba afastando o aluno do ambiente escolar, a teoria da pós avaliação permite alguns pontos que podem ser vistos nos parágrafos abaixo.

Em meio de suas técnicas e através dos primeiros resultados da avaliação, uma interação próxima ao discente de forma que este estruture o modelo avaliativo é a primeira sugestão, visto que a inserção da visão do discente na estruturação da avaliação, permite que este opine e forneça ao professor uma visão de que sua turma não é homogênea.

O uso dessa técnica possibilita, que tanto a avaliação, quanto o professor sejam vistos por outro prisma pelo discente. A prática da pós avaliação pode criar um clima mais amistoso na relação entre estas partes e favorecer a permanência do discente em sala, visto que "a má relação entre professor e aluno, muitas vezes fria, mecânica e distanciada" compõem, segundo 
Auriglietti e SchmidlinLöhr (2014, p.1), "fatores apontados como prejudiciais para a continuidade dos estudos dos jovens."

O não "aproveitamento da aprendizagem pelo aluno em relação ao que é ministrado pelo professor" (Ibidem) é um dos motivos relatados por três professores na publicação Evasão e abandono escolar: causas, consequências e alternativas - o combate à evasão escolar sob a perspectiva dos alunos. Partindo desse pressuposto, a ferramenta da pós-avaliação permite identificar o problema do não aproveitamento no momento em que ele ocorre, permitindo que se trace uma estratégia para envolver os discentes cujo aprendizado não foi satisfatório em novas técnicas de ensino e avaliação a fim de não deixar o problema evoluir a ponto de atingir o nível de evasão escolar.

Como trata-se de uma proposição, a teoria da pós-avaliação tem um longo caminho a percorrer a fim de fornecer maior embasamento teórico e empírico a fim de que os docentes encontrem nela algo para direcionar sua prática e ressignificar, positivamente, sua ação docente.

\section{ASPECTOS METODOLÓGICOS}

Visando cumprir os objetivos traçados, este trabalho utilizou-se de três vieses metodológicos, a saber: a) Pesquisa bibliográfica - visto que todo trabalho acadêmico precisa de um embasamento teórico para apoia sua construção, utiliza-se este modelo de pesquisa para expor as contribuições científicas já existentes acerca do tem (BOCCATO, 2006). Já Gil (1994) mostra que esse modelo é o que melhor define o os conceitos sobre o objeto de estudo proposto.

Visando categorizar a pós-avaliação como um momento que merece atenção, no que tange as publicações a respeito do processo ensino-aprendizagem, utilizou-se a pesquisa do tipo estado da arte, já que esta mapeia a produção cientifica em diversos aspectos como local e época onde foram produzidos.

Por fim, para analisar o cenário atual de como os docentes tratam o momento após a avaliação, foi feita uma pesquisa quali-quantitativa, via formulário no Google Forms, a fim de saber dos docentes como eles dedicam (ou não) tempo para perceber a avaliação da aprendizagem e seus resultados. Os dados foram comparados e analisados através de um programa construído pelo autor do artigo que, de forma randômica, selecionou 15 respostas para traçar o mapa desenhado neste artigo. O programa utiliza o Microsoft Excel como repositório de dados e a linguagem de programação Python, com as bibliotecas pandas, openpyxl, xlrd, xlutils e pyexcel para gerar a amostra, esboçar um comparativo e traçar análise entre os resultados.

Diante deste comparativo, foi empregado um olhar quali-quantitativo que utiliza as características subjetivas da pesquisa, juntamente com os dados numéricos, para traçar um perfil mais próximo da realidade e, segundo Deslandes (1994, p.22), o "conjunto de dados quantitativos e qualitativos [...] não se opõem. Ao contrário, se complementam, pois a realidade abrangida por eles interage dinamicamente, excluindo qualquer dicotomia".

\section{CONSIDERAÇÕES}

Findado o processo de avaliação, temos um resultado que apresenta ao professor a realidade de uma turma. Essa realidade deve, ao menos em teoria, permitir ao professor ressignificar o 
seu trabalho, para que possa proporcionar à turma uma nova oportunidade de assimilar um determinado conteúdo que não ficou claro a todos.

Outro ponto a ser evidenciado é que essa abordagem resultou em um investimento de energia relativamente alto no início, entretanto dois resultados merecem atenção: a) as avaliações posteriores mostraram um aprendizado mais conciso dos alunos que acertaram, em maior grau de profundidade, questões que antes erraram ou tiveram acertos irrisórios; b) o andamento da disciplina a médio e longo prazo se tornou mais fluido. Isso demonstrou que dedicar esforço no momento ideal faz com que, com o real aprendizado fixado na mente, os discentes rendam melhor nos conteúdos que dependem de conhecimentos prévios.

No levantamento feito durante as pesquisas para composição do estado da arte, notou-se uma carência de publicações a cerca desse momento que o pós-avaliar. Isso, demonstrado na Tab. 1 , fornece um embasamento para que docentes e/ou pesquisadores possam contribuir com estudos aplicados a fim de fortalecer a teoria e oportunizar aos discentes, independente de suas particularidades, um acesso mais igualitário ao aprendizado, visto que este é um dos papéis da educação.

\begin{tabular}{|l|c|c|}
\hline \multicolumn{1}{|c|}{ Portal } & $\begin{array}{c}\text { Quantitativo sobre } \\
\text { Avalição }\end{array}$ & $\begin{array}{c}\text { Quantitativo sobre Pós- } \\
\text { Avaliação }\end{array}$ \\
\hline Scielo & 138 & 9 \\
\hline Biblioteca de Teses USP & 3620 & 104 \\
\hline Google Acadêmico & 1.210 .000 & 20 \\
\hline Capes & 437 & 25 \\
\hline
\end{tabular}

Tabela 1 - Estado da arte Avaliação e Pós-Avaliação

Fonte: Próprio Autor (2019)

Um ponto que cabe ser ressaltado é que, dentre os números apresentados na coluna sobre o quantitativo sobre Pós-Avaliação, nenhum dos artigos encontrados estava relacionado à educação. Artigos ligados à áreas como medicina, engenharia, educação física foram encontrados fazendo menção à pós-avaliação, estes com o intuito de medidas justamente relacionadas ao que fazer após avaliar o objeto de cada área. Como é neste mesmo foco o objetivo da teoria aqui disposta, a área de educação apresentou o hiato neste momento do processo de ensino.

O intuito do fortalecimento da teoria é que esta propõe o foco em atacar um problema que impeça um melhor aproveitamento do conteúdo pelo discente, independentemente de onde este se encontre. Empregando a energia de forma otimizada no momento ideal, muitas barreiras podem ser transpostas, como a retenção dos alunos ou a própria evasão do discente - dados que serão observados em estudos futuros.

\section{REFERÊNCIAS}

ANDRADE, Rodrigo de Oliveira. A razão de tantas curvas. Dobras e espessura da camada externa do cérebro não estão relacionadas ao número de neurônios. 2015. Disponível 
em: https://revistapesquisa.fapesp.br/2015/07/15/a-razao-de-tantas-curvas/ Acesso em 30 de julho de 2019.

AUSUBEL, D. P. A aprendizagem significativa: a teoria de David Ausubel. São Paulo: Moraes, 1982.

BOCCATO, V. R. C. Metodologia da pesquisa bibliográfica na área odontológica e o artigo científico como forma de comunicação. Rev. Odontol. Univ. Cidade São Paulo, São Paulo, v. 18, n. 3, p. 265-274, 2006.

DESLANDES, Suely Ferreira. Pesquisa social: teoria, método e criatividade. Petrópolis, RJ. Vozes. 1994.

Díaz, Félix. O processo de aprendizagem e seus transtornos / Félix Díaz. - Salvador : EDUFBA, 2011. 396 p. il.

ESPINOSA, Tracey Tokuhama. A BRIEF HISTORY OF THE SCIENCE OF LEARNING: Part 2 (1970s-present). 2011. Disponível em <

http://archive.education.jhu.edu/PD/newhorizons/Journals/Winter2011/Tokuhama5>. Acesso em <maio de 2019>

FIGUEIREDO, Natália Gomes da Silva. SALLES, Denise Medeiros Ribeiro. Educação

Profissional e evasão escolar em contexto: motivos e reflexões. Universidade Federal Fluminense. Niterói, Rio de Janeiro, Brasil. 2017

GIL, A. C. Métodos e técnicas de pesquisa social. São Paulo: Atlas, 1994.

GRAÇA, Margeylson Ribeiro da. A utilização da internet como mídia para realizações de avaliações multi e hipermidiáticas. 2018a

GRAÇA, Margeylson Ribeiro da. AVALIAÇÃO DA APRENDIZAGEM NAS LINGUAGENS DE PROGRAMAÇÃO: Um estudo no Integrado Informática IFBA Campus Valença. JBTDE. $2018 b$

GRILLO, Marlene Correro. GESSINGER, Rosana Maria. FREITAS, Ana Lúcia Souza de. et al. Por que falar ainda em Avaliação? Porto Alegre. EDIPUCRS, 2010.

GUERRA, Leonor Bezerra. O diálogo entre a neurociência e a educação: da euforia aos desafios e possibilidades. Revista Interlocução, v.4, n.4, p.3-12, publicação semestral, junho/2011.

HOFFMANN, Jussara Maria Lerch. Avaliação mediadora: uma prática em contsrução da pré-escola à universidade - 34 ed - Porto Alegre: Mediação, 2018.

KHAN Academy. The synapse. How neurons communicate with each other at synapses.

Chemical vs. electrical synapses. Sd. Disponível em https://www.khanacademy.org/science/ biology/human-biology/neuron-nervous-system/a/the-synapse acesso em maio de 2019.

KOLB, B.; WHISHAW, I.Q. Neurociência do Comportamento. São Paulo: Manole, 2002.

LUCKESI, Cipriano Carlos. Avaliação da aprendizagem escolar: estudos e proposições $22^{\mathrm{a}} \mathrm{Ed}$ - São Paulo: Cortez, 2011.

MOREIRA, Marco Antônio. Aprendizagem significativa, organizadores prévios, mapas conceituais, diagramas $\mathbf{V}$ e unidades de ensino potencialmente significativas. UFRGS. 2013. Disponível em < http://www.faatensino.com.br/wp-content/uploads/2014/04/ 
Aprendizagem-significativa-Organizadores-pr\%C3\%A9vios-Diagramas-V-Unidades-deensino-potencialmente-significativas.pdf\#page $=41>$ Acesso em 25 de maio de 2018 .

MOURÃO, Carlos Alberto Júnior. FARIA, Nicole Costa. Memória in Psychology/ Psicologia Reflexão e Crítica 28(4), 780-788. 2015

NOVELLA, Steve. Brain Size and Intelligence. 2014. Disponível em

https://theness.com/neurologicablog/index.php/brain-size-and-intelligence-2/. Acesso em 08 de outubro de 2019.

PIAGET, Jean. A epistemologia genética. Trad. de Nathanael C. Caixeiro. $1^{\text {a }}$. ed. Rio de Janeiro: Vozes, 1971.

ROMANZOTI, Natasha. Veja o tamanho e peso do cérebro humano em comparação com outros animais. 2012. Disponível em: https://hypescience.com/veja-o-tamanho-e-peso-docerebro-humano-em-comparacao-com-outros-animais/ Acesso em: 30 de julho de 2019.

AURIGLIETTI, Rosangela Cristina Rocha. SCHMIDLINLÖHR, Suzane. Evasão e abandono escolar: causas, consequências e alternativas - o combate a evasão escolar sob a perspectiva dos alunos in Os desafios da escola pública paranaense na perspectiva do professor PDE. 2014. Disponível em http://www.diaadiaeducacao.pr.gov.br/portals/ cadernospde/pdebusca/producoes_pde/2014/2014_ufpr_ped_artigo_rosangela_cristina_rocha .pdf. Acesso em 09 de outubro de 2019

SANT'ANNA, Ilza Martins. Por que avaliar? Como avaliar?: Critérios e instrumentos. $3^{a}$ Edição, Petrópolis, RJ: Vozes, 2010. 